\title{
Detection and Modeling of Phosphorus in Water Quality Monitoring Programs
}

\author{
Qiaoling $\mathrm{Du}^{1}$, Zenghua Ren ${ }^{2}$, Zhenze $\mathrm{Liu}^{3}$, Yiding Wang ${ }^{1 *}$ \\ ${ }^{1}$ College of Electronic Science and Engineering, Jilin University, Changchun, 130012, China \\ ${ }^{2} 2$ Tuanjie Road, Baishan City, Jilin Province, 134305, China \\ ${ }^{3}$ College of Communication Engineering, Jilin University, Changchun, 130012, China
}

\begin{abstract}
Understanding the impact of phosphorus is essential to ensure water quality. Excessive nutrient loading, primarily phosphorus (P), is one of the vital reason for eutrophic. In this paper a survey concerning the concentration of phosphorus in a reservoir of northeast China was carried out. The raw data was collected monthly and a 19data setsmonthly were collected from January2011 to July2012. The purpose of this investigation is to understand how phosphorus would affect the average annual water quality. A specific empirical model is proposed to show the dynamics of phosphorus level variation in reservoir. The model was presented to show water quality levels in response to various phosphorus levels. The simulation results can be an important reference for the evaluation of nutrient loads.
\end{abstract}

Keywords-water quality monitoring; phosphorus; water temperature; reservoir.

\section{INTRODUCTION}

The restoration of reservoirs serving as municipal water supplies and drinking water, is recognized as one of the most widespread problems in water quality management. Eutrophication of water quality has become one of the water quality issues in reservoirs. Phosphorus $(\mathrm{P})$ is regarded asa primary or contributing nutrient to freshwater eutrophication.

Some research has been focused on water quality pollution caused by phosphorus. M. Taheriyounet al. proposed anew method called entropy-based fuzzy synthetic evaluation method, that obtained the uncertainties and randomness in the raw data and developed EFEI to determine the trophic status in the SatarkhanReservoir[1]. Vera Istva'novicset al.developeda program that complemented lake-specific ecological criteria within the range existing and concluded that the simple objectivesare the good choice in the initial stages of eutrophication management[2]. Dale M.et al. applied eutrophication programs to three different application, includingthe Seepage Lake, BATHTUB, and WiLMSModel to verify specific empirical models Model[3]. Simulation results show that the reduction of external $\mathrm{P}$ load would reduce near-surface TP. Josef S. Kardoset al. examined the impact of water quality model uncertainty on the nutritional trading scheme, and designed a scheme that would be implemented watershed TMDL for Nontidal Passaic River in New Jersey [4]. This papers howed how the uncertainty of water quality model affects the results on potential trades between the sewage treatment plants. M. Tarvainenet al. estimated phosphorus release with a bioenergetics model, that made use of data from roach diet and growth, and estimated the phosphorus release from different age roach groups to determine whether phosphorus released by the fish can determinate the observed increase in the phosphorus concentration in the summer[5].Dennis Trolleet al. tested Taihu Lake sediment nitrogen content and the phosphorus changing with vertical and horizontal variations [6]. Stepwise linear regression analysis showed that $91 \%$ of the horizontal variability in the sediment total phosphorous concentration and $65 \%$ of the vertical variation was due to the combination of carbon concentration and sediment manganese.

In this paper Fuzzy Inference System was developed to assess trophic evaluation of reservoirs. Five water quality parameters of total phosphorous (TP), chlorophyll a, secchi depth (SD), hypolimnetic oxygen ( $\mathrm{HO} \%$ ), and total nitrogen (TN) were monitored. The raw data was collected monthly and a 19data set monthly was collected from January 2011 to July2012. The purpose of this investigation is to understand how phosphorus would affect the reservoir eutrophication level. The simulation results can be an important reference for the evaluation of nutrient loads. This result indicated that the methodology adopted in this study was basically an attractive alternative, offering a relatively fast algorithm to assess trophic evaluation of reservoirs.

The remaining sections of this paper are organized as follows. Section 2 presents the developed Fuzzy Inference System and the entropy weighing method. Section 3 presents MATLAB simulation is detailed. The paper concludes with Section 4.

\section{MATERIALS AND METHODS}

Data used for the reservoir eutrophication level in northeast China are monthly records from January 2011 to July2012. A 19 data sets monthly were collected from January 2011 to July2012. Five water quality parameters used in this study analysis are total phosphorous (TP), chlorophyll a, secchi depth (SD), hypolimnetic oxygen $(\mathrm{HO} \%)$, and total nitrogen (TN). See Table 1 for specific values of the parameter sampling.

In this study, Fuzzy Inference System was developed to assess trophic evaluation of reservoirs. The assessment criteria is established from the OECD eutrophication 
program (modified from Vollenweider and Kerekes, OECD, 1982)[7]. Table 2 presents the assessment criteria in detail.

Let $U$ be an evaluation factor set based on water quality parameters. $U$ be represented as follows:

$$
\mathrm{U}=\left\{\mathrm{u}_{\mathrm{i}}\right\}, \mathrm{i}=1,2, \cdots, \mathrm{n}
$$

TABLE I. WATER QUALITY DATA DURING JANUARY 2011- JULY 2012(MG L ${ }^{-1}$ )

\begin{tabular}{|c|c|c|c|c|c|c|c|c|c|c|c|c|}
\hline \multirow{2}{*}{ Parameters } & \multicolumn{12}{|c|}{2011} \\
\hline & 1 & 2 & 3 & 4 & 5 & 6 & 7 & 8 & 9 & 10 & 11 & 12 \\
\hline chlorophyll a & 6.0 & 4.0 & 1.0 & 1.0 & 8.0 & 5.0 & 2.0 & 9.0 & 12.0 & 3.0 & 1.0 & 1.0 \\
\hline TP & 10 & 40 & 50 & 70 & 40 & 40 & 30 & 30 & 10 & 70 & 10 & $<\mathrm{DL}$ \\
\hline $\mathrm{TN}(\mathrm{mg})$ & 3.81 & 4.62 & 5.18 & 3.81 & 3.01 & 3.65 & 2.68 & 2.52 & 2.96 & 3.57 & 3.46 & 3.05 \\
\hline SD & 1 & 1 & 3 & 2 & 1 & 2 & 2 & 2 & 2 & 3 & 3 & 3 \\
\hline $\mathrm{HO}$ & 8.4 & 6.5 & 8.0 & 8.1 & 10.1 & 7.0 & 8.1 & 8.5 & 8.5 & 7.0 & 7.9 & 9.6 \\
\hline \multirow{2}{*}{ Parameters } & \multicolumn{7}{|c|}{2012} & & & & & \\
\hline & 1 & 2 & 3 & 4 & 5 & 6 & 7 & & & & & \\
\hline chlorophyll a & 6.0 & 2.0 & 2.0 & 1.0 & 1.0 & 6.0 & 16 & & & & & \\
\hline TP & 40 & 40 & 30 & 90 & 30 & 50 & 40 & & & & & \\
\hline $\mathrm{TN}(\mathrm{mg})$ & 3.23 & 3.24 & 3.06 & 3.95 & 4.48 & 3.22 & 3.67 & & & & & \\
\hline SD & 3 & 2 & 3 & 2 & 2 & 2 & 1 & & & & & \\
\hline $\mathrm{HO}$ & 9.8 & 8.8 & 10.4 & 5.4 & 10.5 & 8.6 & 9.1 & & & & & \\
\hline
\end{tabular}

TABLE II. CLASSIFICATION PROGRAM OF TROPHIC STATUS

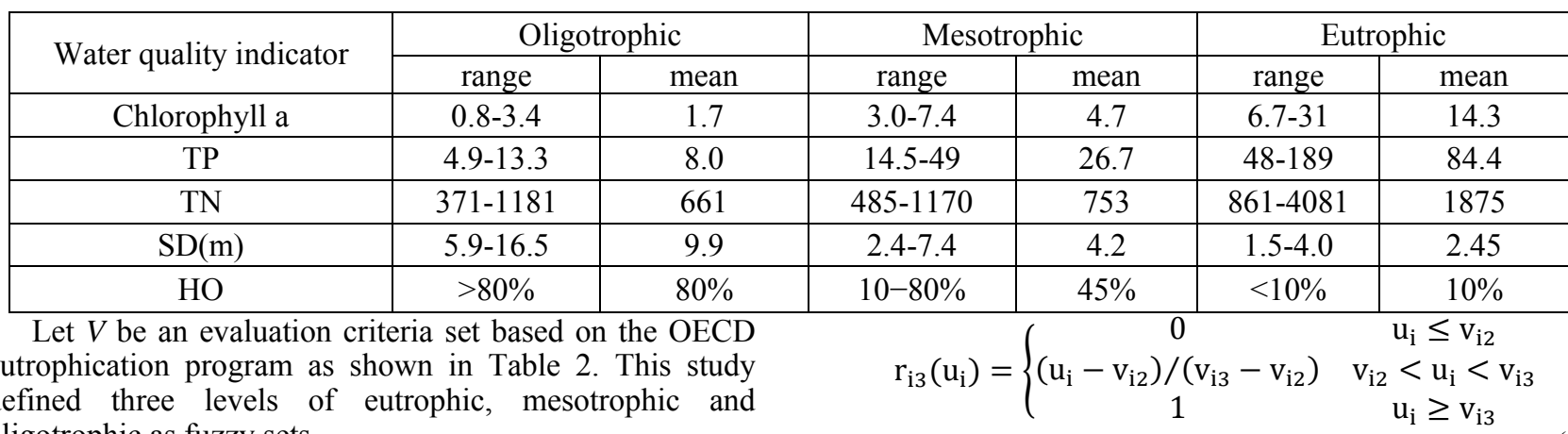

(4) oligotrophic as fuzzy sets.

$$
V=\left\{v_{i j}\right\}, i=1,2, \cdots, n ; j=1,2, \cdots, m
$$

Where $v_{i j}$ is the criteria mean value of the $i^{\text {th }}$ assessment parameter at the $j^{\text {th }}$ level.

The fuzzy relation $R$ between $U$ and $V$ is given by

$$
R=\left(\begin{array}{ccc}
\mathrm{r}_{11} & \cdots & \mathrm{r}_{1 \mathrm{~m}} \\
\vdots & \ddots & \vdots \\
\mathrm{r}_{\mathrm{n} 1} & \cdots & \mathrm{r}_{\mathrm{nm}}
\end{array}\right)
$$

Eq.(4) demonstrates the membership function for the water quality assessment parameter, the smaller the better such as chlorophyll a, TP and TN.

$$
\begin{aligned}
& r_{i 1}\left(u_{i}\right)=\left\{\begin{array}{cc}
1 & u_{i} \leq v_{i 1} \\
\left(u_{i}-v_{i 2}\right) /\left(v_{i 1}-v_{i 2}\right) & v_{i 1}<u_{i}<v_{i 2} \\
0 & u_{i} \geq v_{i 2}
\end{array}\right. \\
& r_{i 2}\left(u_{i}\right)=\left\{\begin{array}{cc}
u_{i} \leq v_{i 1} \\
\left(u_{i}-v_{i 1}\right) /\left(v_{i 2}-v_{i 1}\right) & v_{i 1}<u_{i} \leq v_{i 2} \\
\left(u_{i}-v_{i 3}\right) /\left(v_{i 2}-v_{i 3}\right) & v_{i 2}<u_{i}<v_{i 3} \\
0 & u_{i} \geq v_{i 3}
\end{array}\right.
\end{aligned}
$$

For the water quality assessment parameter, the bigger the better such as SD and $\mathrm{HO}$, the membership functions are

$$
\begin{aligned}
& \begin{array}{cc}
1 & u_{i} \geq v_{i 1}
\end{array} \\
& r_{i 1}\left(u_{i}\right)=\left\{\begin{array}{cc}
\left(u_{i}-v_{i 2}\right) /\left(v_{i 1}-v_{i 2}\right) & v_{i 2}<u_{i}<v_{i 1} \\
0 & u_{i}
\end{array}\right. \\
& \left\{\begin{array}{cc}
0 & u_{i} \geq v_{i 1}
\end{array}\right. \\
& r_{i 2}\left(u_{i}\right)=\left\{\begin{array}{cc}
\left(u_{i}-v_{i 1}\right) /\left(v_{i 2}-v_{i 1}\right) & v_{i 2}<u_{i} \leq v_{i 1} \\
\left(u_{i}-v_{i 3}\right) /\left(v_{i 2}-v_{i 3}\right) & v_{i 3}<u_{i}<v_{i 2} \\
0 &
\end{array}\right. \\
& \left\{\begin{array}{cc}
0 & u_{i} \geq v_{i 2}
\end{array}\right. \\
& r_{i 3}\left(u_{i}\right)=\left\{\begin{array}{cc}
\left(u_{i}-v_{i 2}\right) /\left(v_{i 3}-v_{i 2}\right) & \left.v_{i 3}<u_{i}<v_{i 2}\right) \\
1 & u_{i} v_{i 2}
\end{array}\right.
\end{aligned}
$$

In order to evaluate the impact of different parameters that could affect the reservoir eutrophication level, the entropy weighing method is introduced to calculate the water parameters weight related on eutrophication.

Let $X$ denote the matrix of $l$ samples for five water quality parameters as shown in Eq. (6). 


$$
\mathrm{X}=\left[\begin{array}{ccc}
\mathrm{X}_{11} & \cdots & \mathrm{X}_{1 \mathrm{n}} \\
\vdots & \ddots & \vdots \\
\mathrm{X}_{\mathrm{l} 1} & \cdots & \mathrm{X}_{\mathrm{mn}}
\end{array}\right]
$$

Where $X_{i j}$ represents the $i^{\text {th }}$ sample for the $j^{\text {th }}$ parameter $(i=1,2, \cdots, l ; j=1,2, \cdots, n)$.

The elements of the evaluation matrix can be normalized by maximum criterion as shown in Eq. (7).

$$
\mathrm{r}_{\mathrm{ij}}=\frac{\mathrm{x}_{\mathrm{ij}}}{\max \left\{\mathrm{x}_{\mathrm{ij}}\right\}_{\mathrm{j}}}
$$

The weight vector $\mathrm{W}=\left\{\mathrm{w}_{\mathrm{i}}\right\}, \mathrm{i}=1,2, \cdots, \mathrm{n}$ is defined as[7]:

Where

$$
\begin{gathered}
\mathrm{w}_{\mathrm{i}}=\left(1-\mathrm{E}_{\mathrm{i}}\right) / \sum_{\mathrm{i}=1}^{\mathrm{n}}\left(1-\mathrm{E}_{\mathrm{i}}\right) \\
\mathrm{E}_{\mathrm{i}}=-\mathrm{C} \sum_{\mathrm{j}=1}^{\mathrm{n}}\left(\mathrm{P}_{\mathrm{ji}} \mathrm{LnP}_{\mathrm{ji}}\right) \\
\mathrm{P}_{\mathrm{ji}}=\mathrm{r}_{\mathrm{ji}} / \sum_{\mathrm{i}=1}^{\mathrm{n}} \mathrm{r}_{\mathrm{ji}}
\end{gathered}
$$

\section{SimUlATION}

Based on the original monitoring data (Table 1) including 19 data set monthly $(l=19)$ and 5 parameters $(m=5)$. The weight vector of chlorophyll a, TP, TN SD, and $\mathrm{HO}$ using Eq. 8 is calculated as follows:

$$
\mathrm{W}=\left[\begin{array}{lllll}
0.59 & 0.26 & 0.03 & 0.10 & 0.02
\end{array}\right]
$$

$$
\mathrm{B}=\mathrm{W} \times \mathrm{R}
$$

whereW $=\left\{w_{i}\right\}, i=1,2, \cdots, n$.

A Evaluation result is through maximizing element in matrix $B=\left\{b_{i}\right\}, i=1,2, \cdots, m$ as shown in Eq. (13).

$$
\text { Level }=\max \left(b_{i}\right), i=1,2, \cdots, m
$$

Table 3 presents the membership values calculated by evaluation matrix based on three different trophic status levels and the evaluation result of trophic level by maximum criterion.

January, March, April, October, November and December during low temperature season were assessed as oligotrophic level since the low temperatures lead to low chlorophyll a concentration. June and July were mesotrophicdue to increase both total phosphorous and chlorophylla. August and September were eutrophic due to the high concentration of both total phosphorous andchlorophylla. But May different from both April and June was belong to eutrophic mainly because of total

\begin{tabular}{|c|c|c|c|c|c|c|c|c|c|c|}
\hline Month & 1 & 2 & 3 & 4 & 5 & 6 & 7 & 8 & 9 & 10 \\
\hline $\mathrm{E}$ & 0.13 & 0.10 & 0.21 & 0.32 & 0.34 & 0.14 & 0.14 & 0.41 & 0.60 & 0.32 \\
\hline M & 0.00 & 0.66 & 0.10 & 0.10 & 0.30 & 0.77 & 0.75 & 0.24 & 0.05 & 0.30 \\
\hline $\mathrm{O}$ & 0.76 & 0.20 & 0.61 & 0.61 & 0.20 & 0.02 & 0.02 & 0.25 & 0.25 & 0.34 \\
\hline trophic level & $\mathrm{O}$ & M & $\mathrm{O}$ & $\mathrm{O}$ & $\mathrm{E}$ & M & $\mathrm{M}$ & $\mathrm{E}$ & $\mathrm{E}$ & $\mathrm{O}$ \\
\hline Month & 11 & 12 & 1 & 2 & 3 & 4 & 5 & 6 & 7 & \\
\hline E & 0.13 & 0.13 & 0.13 & 0.13 & 0.13 & 0.39 & 0.10 & 0.24 & 0.73 & \\
\hline M & 0.00 & 0.00 & 0.70 & 0.20 & 0.24 & 0.02 & 0.24 & 0.51 & 0.20 & \\
\hline $\mathrm{O}$ & 0.82 & 0.84 & 0.02 & 0.60 & 0.55 & 0.59 & 0.62 & 0.20 & 0.07 & \\
\hline trophic level & $\mathrm{O}$ & $\mathrm{O}$ & M & $\mathrm{O}$ & $\mathrm{O}$ & $\mathrm{O}$ & $\mathrm{O}$ & M & E & \\
\hline
\end{tabular}
phosphorous increasing suddenly. The sudden increase in TP was due to farmland fertilizer flowing into reservoir in the spring season. In 2012, reservoir management was enhanced, this situation does not occur again and May was assessed as oligotrophic.

TABle III. Month LEVEl Of TROPHIC StATUS

$\mathrm{O}=$ oligotrophic, $\mathrm{M}=$ mesotrophic and $\mathrm{E}=$ eutrophic

\section{CONCLUSION}

In this paper Fuzzy Inference System was developed to assess trophic evaluation of reservoirs. The assessment criteria is established from the OECD eutrophication program (modified from Vollenweider and Kerekes, OECD, 1982). Five water quality parameters of total phosphorous (TP), chlorophyll a, secchi depth (SD), hypolimnetic oxygen $(\mathrm{HO} \%)$, and total nitrogen $(\mathrm{TN})$ were monitored. In order to evaluate the impact of different parameters that could affect the reservoir eutrophication level, the entropy weighing method is introduced to calculate the water parameters weight related on eutrophication. The simulation results can be an important reference for the evaluation of nutrient loads.

\section{V.ACKNOWLEDGEMENTS}

This study was supported by NNSF of China (61001006), Jilin province science and technology development plan item (201101026) and CSC projectas well as the Basic Theory fund for Underwater wireless communication channel estimation and communication performance in Jilin University(450060491322).

\section{REFERENCES}

[1] Taheriyoun Met al. Development of an entropy-based fuzzy eutrophication index for reservoir water quality evaluation. Iranian Journal of Environmental Health Science \& Engineering, 2010, 7(1).

[2] Istvánovics Vet al. Updating water quality targets for shallow Lake Balaton (Hungary), recovering from eutrophication.Springer Netherlands, 2007: 305-318.

[3] Robertson D M, Schladow S G. Response in the water quality of the Salton Sea, California, to changes in phosphorus loading: an empirical modeling approach. The Salton Sea Centennial Symposium. Springer Netherlands, 2008: 5-19.

[4] Kardos J S, Obropta C. Water Quality Model Uncertainty Analysis of a Point-Point Source Phosphorus Trading Program1. JAWRA Journal of the American Water Resources Association, 2011, 47(6): 1317-1337.

[5] Tarvainen $M$, et al. The role of phosphorus release by roach [Rutilusrutilus (L.)] in the water quality changes of a biomanipulated lake.Freshwater biology, 2002, 47(12): 2325-2336. 
[6] Trolle D, et al.The influence of water quality and sediment geochemistry on the horizontal and vertical distribution of phosphorus and nitrogen in sediments of a large, shallow lake.Hydrobiologia, 2009, 627(1): 31-44.
[7] Zurlini G. Multiparametric classification of trophic conditions. The OECD methodology extended: combined probabilities and uncertainties - application to the North Adriatic Sea. Science of the total environment, 1996, 182(1): 169-185 